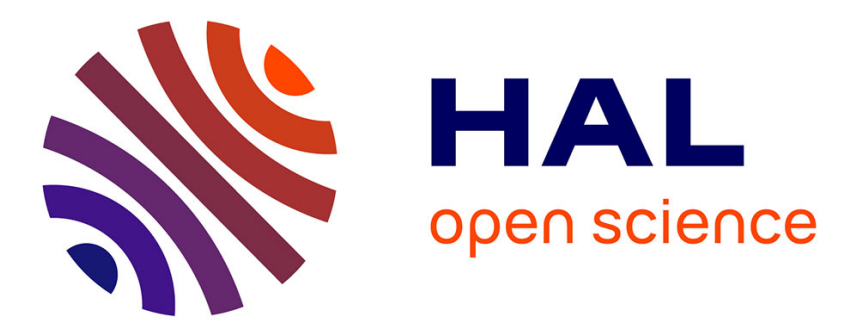

\title{
Influence of silver nanowires on thermal and electrical behaviors of a poly(epoxy) coating for aeronautical application
}

\author{
Vincent Bedel, Antoine Lonjon, Eric Dantras, Michel Bouquet
}

\section{To cite this version:}

Vincent Bedel, Antoine Lonjon, Eric Dantras, Michel Bouquet. Influence of silver nanowires on thermal and electrical behaviors of a poly(epoxy) coating for aeronautical application. Journal of Applied Polymer Science, 2018, 135 (47), pp.1-9. 10.1002/APP.46829 . hal-01962096

\section{HAL Id: hal-01962096 https://hal.science/hal-01962096}

Submitted on 20 Dec 2018

HAL is a multi-disciplinary open access archive for the deposit and dissemination of scientific research documents, whether they are published or not. The documents may come from teaching and research institutions in France or abroad, or from public or private research centers.
L'archive ouverte pluridisciplinaire $\mathbf{H A L}$, est destinée au dépôt et à la diffusion de documents scientifiques de niveau recherche, publiés ou non, émanant des établissements d'enseignement et de recherche français ou étrangers, des laboratoires publics ou privés. 


\section{Open Archive Toulouse Archive Ouverte (OATAO)}

OATAO is an open access repository that collects the work of Toulouse researchers and makes it freely available over the web where possible

This is an author's version published in: http://oatao.univ-toulouse.fr/ 20886

Official URL: https://doi.org/10.1002/APP.46829

\section{To cite this version:}

Bedel, Vincent $\leftrightarrows$ and Lonjon, Antoine Bouquet, Michel $\doteq$ Influence of silver nanowires on thermal and electrical behaviors of a poly(epoxy) coating for aeronautical application. (2018) Journal of Applied Polymer Science, 135 (47). 1-9. ISSN 0021-8995

Any correspondence concerning this service should be sent to the repository administrator: tech-oatao@listes-diff.inp-toulouse.fr 


\title{
Influence of silver nanowires on thermal and electrical behaviors of a poly(epoxy) coating for aeronautical application
}

\author{
Vincent Bedel, ${ }^{1,2}$ Antoine Lonjon ${ }^{1}{ }^{1}$ Éric Dantras, ${ }^{1}$ Michel Bouquet ${ }^{2}$ \\ ${ }^{1}$ Physique des Polymères, CIRIMAT, Université de Toulouse, CNRS, 118 route de Narbonne, 31062, Toulouse cedex 09, France \\ ${ }^{2}$ Institut de Recherche Technologique (IRT) Saint Exupéry, 118 route de Narbonne, CS 44248, 31432, Toulouse cedex 4, France \\ Correspondence to: A. Lonjon (E-mail: antoine.lonjon@univ-tlse3.fr)
}

\begin{abstract}
Thermal and electrical behaviors of a poly(epoxy) coating with high electrical conductivity used for aeronautic applications are investigated. The poly(epoxy) used is designed for resin transfer molding (RTM) applications, it have a low viscosity at room temperature (around $1 \mathrm{~Pa} \mathrm{~s}$ ) and a high $T_{g}\left(>160^{\circ} \mathrm{C}\right)$. This study details the influence of silver nanowires with a high aspect ratio, on the thermal behavior such as the relative degree of reaction $\alpha$ and the kinetics parameters thanks to dynamic and isothermal differential scanning calorimetry. Conductivity measurements of surface and volume have permitted to determine a very low percolation threshold at around $0.7 \%$ in volume. The value of electrical conductivity above the percolation threshold is upper than $10^{2} \mathrm{~S} \mathrm{~m}^{-1}$ and the lowest surface resistivity was measured around $13 \mathrm{~m} \Omega \mathrm{sq}^{-1}$ both for $8 \%$ in volume of AgNWs. This kind of coating has a great interest for lightning strike protection of aircraft parts due to the high electrical conductivity obtained with a low overweight. ๑ 2018 Wiley Periodicals, Inc. J. Appl. Polym. Sci. 2018, 135, 46829.
\end{abstract}

KEYWORDS: coatings; conductive polymer composites; differential scanning calorimetry (DSC); kinetics; nanowires

DOI: 10.1002/app.46829

\section{INTRODUCTION}

During the last decades, the use of polymer matrix composites in the aeronautic sector is in steady increase. ${ }^{1}$ Thermoset matrices are widely used for structural applications. ${ }^{2}$ Carbon fiber reinforced polymers (CFRPs) have a poor electrical conductivity, about $10^{-2} \mathrm{~S} \mathrm{~m}^{-1}{ }^{3}$, versus $10^{8} \mathrm{~S} \mathrm{~m}^{-1}$ for an aluminum part. In case of lightning strike, the structure could be damaged, and so the actual challenge is to improve the conductivity of CFRP. The first approach was the introduction of carbon fillers in polymeric matrix. In the case of carbon black, ${ }^{4}$ the amount to obtain percolation threshold is about $15 \%$ in volume which decreases mechanical properties. Sandler et al., ${ }^{5}$ Barrau et al., ${ }^{6}$ and Causse et $a .^{7}$ have introduced carbon nanotubes (CNTs) in epoxy polymer matrix. They obtained a percolation threshold about $0.03 \%$ in volume allowing them to preserve the mechanical properties. Graphene is also used to obtain a percolation threshold below $1 \%$ in volume. ${ }^{8,9}$ Independently of the morphology, the best electrical conductivity value is about $10^{-1} \mathrm{~S} \mathrm{~m}^{-1}$ due to the chemical nature of the carbon filler. ${ }^{10}$ The bulk conductivity of carbon is around $10^{5} \mathrm{~S} \mathrm{~m}^{-1}$. This value is enough to dissipate electrostatic charges but not for a lightning strike (up to $200 \mathrm{kA}$ ). ${ }^{11}$ Today, an expended cooper foil is applied on the top of structural plies. ${ }^{12,13}$ This solution is complex to process due to the rigidity of the foil and induces a slight overweight of the composite parts. Another way is the introduction of metallic fillers in the polymer matrix. Gurland ${ }^{14}$ has made an experimental dispersion of silver particles in polymer matrix. The electrical conductivity level was about $10^{3} \mathrm{~S} \mathrm{~m}^{-1}$ for $40 \%$ in volume. This high ratio of fillers drastically reduces the mechanical properties and increases the weight. Different kinds of metals were tested like gold, copper, and nickel. ${ }^{15-21}$ The level of conductivity with metallic fillers, dispersed homogeneously is about $10^{2} \mathrm{~S} \mathrm{~m}^{-1}$. Following the CNT example, the increase of the aspect ratio has permitted to reduce the percolation threshold, to obtain a conductive behavior and to keep mechanical properties of the matrix. ${ }^{22-25}$

The aim of this work is to study the influence of $1 \mathrm{D}$ metallic filler on the epoxy matrix polymerization kinetic. This $3 \mathrm{D}$ thermoset is used to develop a high electrical conductive coating for low filler content $(<8 \%$ vol) to be used for electric charges dissipation on aeronautical surface parts. First, the influence of stoichiometric ratio between hardener and resin on the relative degree of conversion and on the polymerization kinetic is studied for different storage temperatures. Then, experimentations were carried out to determine the influence of metallic fillers on these parameters. To conclude a study of the electrical behavior of this composite as a function of metallic filler ratio was proposed. 


\section{EXPERIMENTAL}

\section{Matrix}

The epoxy matrix used in this study is a mixture of $4,4^{\prime}$-methylenebis $(N, N$-diglycidylaniline, diglycidyl ether of bisphenol A (DGEBA), and diglycidyl ether of bisphenol-F. The amine hardener is composed by a diethyltoluenediamine and a 1,2 diaminocyclohexane supplied by Sicomin for RTM structural applications.

\section{Nanowires}

The aim is to develop a highly conductive coating with low filler ratio: that is, less than $8 \%$ in volume. This value is the limit for a spraying process. Metallic fillers are silver nanowires (AgNWs), first developed by Sun et al. ${ }^{26,27}$ and then Wiley et al. ${ }^{28}$ AgNWs are synthesized with a polyol process by reducing $\mathrm{AgNO}_{3}$ with ethylene glycol solution. The growth is assisted by poly(vinylpyrrolidone) which is preferentially adsorbed on $\{100\}$ crystal faces of the silver seeds. The reaction occurs at $165{ }^{\circ} \mathrm{C}$ under stirring in three-necked round-bottom flask during $40 \mathrm{~min}$. The ratio between the reactants was adapted. ${ }^{24,25}$ AgNWs are washed and stored in ethanol and the aspect ratio is around 220 (about $40 \mu \mathrm{m}$ in length and $180 \mathrm{~nm}$ in diameter). ${ }^{25}$ This method allows us to obtain large quantity up to $100 \mathrm{~g}$.

\section{Composite Processing}

Composites were obtained by mixing AgNWs dispersed in ethanol in the epoxy part. The mixture is heated up to evaporate the ethanol during $20 \mathrm{~min}$ at $100{ }^{\circ} \mathrm{C}$. After cooling at room temperature, the hardener is poured. The mixing was obtained by mechanical and ultrasonic stirring for few minute. The mixture is usually cured by different steps between 40 and $200{ }^{\circ} \mathrm{C}$.

The AgNWs content is determined by thermogravimetric analysis (TGA) from room temperature to $1000{ }^{\circ} \mathrm{C}$ at a heating rate of $20^{\circ} \mathrm{C} \mathrm{min}^{-1}$ under synthetic air atmosphere.

\section{Scanning Electron Microscopy}

The quality of the dispersion is checked by scanning electronic microscopy (SEM) on a JEOL JSM 6700F instrument under a voltage of $19 \mathrm{keV}$. Backscattered electron detection mode was used to increase the contrast between AgNWs and the poly(epoxy) matrix. The edge cut was obtained by breaking at room temperature due to the specific rigidity of the matrix.

\section{Differential Scanning Calorimetry}

The thermal stability of the matrix was evaluated by TGA at the isotherm $280^{\circ} \mathrm{C}$. The relative degree of conversion and the polymerization kinetics are determined by differential scanning calorimetry (DSC) on a DSC 2920 (Thermal Analysis Instruments) for different thermal processing. The sample weight is about $10 \mathrm{mg}$ which are placed into aluminum pans. Two types of analyses were carried out: isothermal and dynamic experiment. For the last one, samples were prepared and heated at a temperature between 30 and $60{ }^{\circ} \mathrm{C}$. They were removed every $30 \mathrm{~min}$. Then, the crosslinking enthalpy was evaluated from 20 to $280{ }^{\circ} \mathrm{C}$ at a heating rate of $20{ }^{\circ} \mathrm{C} \mathrm{min}{ }^{-1}$ under helium atmosphere. The relative degree of reaction $\alpha$ is determined with eq. (1):

$$
\alpha=\frac{\Delta H_{t=0}-\Delta H_{t}}{\Delta H_{t=0}}
$$

with $\alpha$ the relative degree of reaction, $\Delta H_{t=0}$ the initial crosslinking enthalpy value and $\Delta H_{t}$ the crosslinking enthalpy value at a specific time $t$.

The isothermal analyses permitted us to determine the polymerization kinetic as a function of the conversion degree. Then, the experimental results were fitted with the following autocatalytic model. $^{29,30}$

$$
\begin{gathered}
\frac{d \alpha}{d t}=\frac{d H / d t}{\Delta H_{t=0}} \\
\frac{d \alpha}{d t}=k \alpha^{m}\left(\alpha_{\max }-\alpha\right)^{n}
\end{gathered}
$$

where $d \alpha / d t$ is the cure kinetic, the $m$ and $n$ parameters are partials order of reaction, which are temperature independent, $k$ is a rate constant which depends on temperature by an Arrhenius law and $\alpha_{\max }$ is the maximum degree of the reaction for the experimental temperature (from 30 to $60{ }^{\circ} \mathrm{C}$ ).

\section{Electrical Conductivity}

The surface and bulk conductivity measurements were performed with a Keithley 2420 Multimeter and a dynamic dielectric spectrometer BDS 4000 (Novocontrol, Germany) for the lowest levels of conductivity (impedance sample $\mathrm{Z}>10 \Omega$ ). Surface conductivity is determined following the ASTM Standard D4496-87 on a thin coating (between 50 and $100 \mu \mathrm{m}$ ) applied on CFRP substrate by a pneumatic spraying method. Volume conductivity is obtained by using discs $40 \mathrm{~mm}$ in diameter and about $500 \mu \mathrm{m}$ thick.

Electrical measurements performed with the multimeter were obtained by a four wires method to decrease the influence of the current on the voltage measurement.

The lowest conductivities are determined by dielectric spectroscopy at room temperature in the frequency range of $10^{-2}$ $10^{6} \mathrm{~Hz}$. In a disordered matrix, the real part of the electrical conductivity depends on the frequency following Jonscher's universal dielectric relaxation law:

$$
\sigma^{\prime}(\omega)=\sigma_{\mathrm{DC}}+A \omega^{s}
$$

where $\sigma^{\prime}(\omega)$ is the real part of the conductivity, $\sigma_{\mathrm{DC}}$ is the static conductivity, $A$ is a constant depending on the temperature, $\omega$ is the angular frequency, and $s$ is an exponent between 0 and 1 with a double dependency, temperature, and frequency. In this configuration, the sample is inserted between two $40 \mathrm{~mm}$ gold plated electrodes.

\section{RESULTS AND DISCUSSION}

\section{Nanowires Dispersion in the Matrix}

AgNWs dispersion in the polymeric matrix was observed with a SEM. Surface observation [Figure 1(a)] and transversal observation of the edge cut [Figure 1(b)] show a homogenous dispersion, a slight orientation of the AgNWs due to the process and a preservation of the high aspect ratio after spraying process. The thickness of the nanocomposite coating is about $50 \mu \mathrm{m}$.

\section{Calorimetric Study of the Neat Matrix}

The poly(epoxy) is obtained by mixing the epoxide resin and amine hardener. Commercial stoichiometric proportion between 

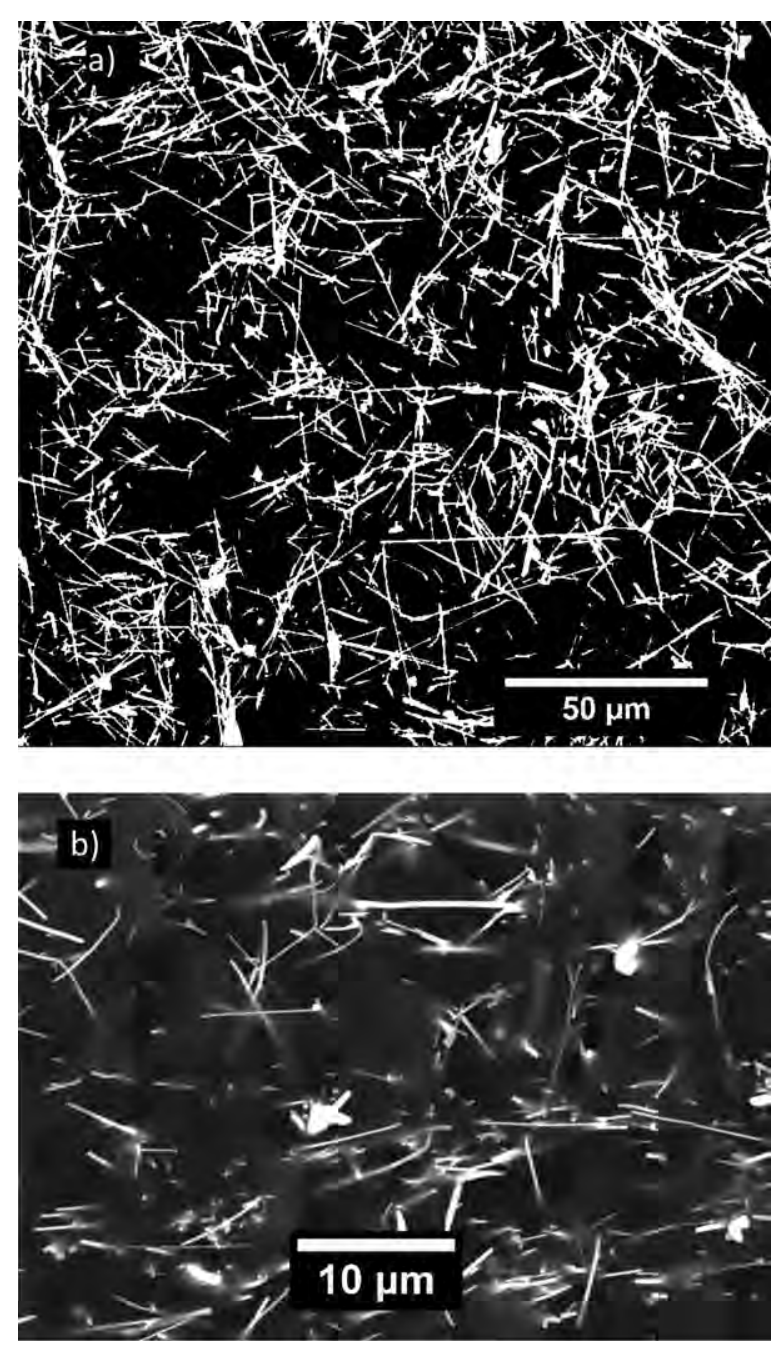

Figure 1. SEM images of poly(epoxy)/Ag 2\%vol AgNWs: (a) surface and (b) edge cut of coating.

the resin and the hardener is $79 / 21$. In this work, the proportion chosen is $75 / 25$, with an excess of the hardener due to its solubility with the solvents used, acetone and ethanol. During the spraying process, a slight quantity of hardener is evaporated. To obtain an optimal crosslinking, an excess of hardener is necessary.

Calorimetric Method and Stoichiometric Ratio Influence. A study was carried out to determine the system's physical parameters like glass-transition temperature $\left(T_{g}\right)$ or crosslinking enthalpy as a function of the stoichiometric ratio.

Figure 2 represents the thermogram before and after polymerization. The resin glass-transition temperature is around $-45^{\circ} \mathrm{C}$, the polymerization starts around $80{ }^{\circ} \mathrm{C}$ with a maximum at 130 ${ }^{\circ} \mathrm{C}$. Table I shows the influence of the stoichiometric ratio. $T_{g}$ is slightly lower for the $75 / 25$ than for $79 / 21$ ratio, due to a faster gelation of the $3 \mathrm{D}$ network. The sequences quantities which have not reacted are higher with an excess of hardener. Dynamic DSC experiments were carried out to determine the conversion degree for different thermal environments between 30 and $60{ }^{\circ} \mathrm{C}$.
Figure 3 shows the influence of the stoichiometric ratio on the relative degree of reaction in dynamic experiment. An excess hardener is responsible for a decrease about $9 \%$ of the maximum relative degree of reaction for the different temperatures: it is the consequence of a faster 3D network formation with a high quantity of unreacted sequences; associated with a mobility decrease due to the gelation.

A similar study was carried out during isothermal measurement to compare these two methods (Figure 4). Overall, the maximum of conversion degree is similar. However, there is a modification of the thermal behavior between dynamic and isothermal studies. At $40{ }^{\circ} \mathrm{C}$ for the same duration, the relative degree of reaction $\alpha$ is higher for dynamic measurement. This difference is due to the formation of a catalyzer at a temperature higher than $40{ }^{\circ} \mathrm{C}$; that is, hydroxyl group. Riccardi et al. ${ }^{31}$ and Horie et al. ${ }^{32}$ observed this phenomenon, which is the characteristic of an autocatalytic reaction.

Kinetic Study of Polymerization. The reaction kinetic was determined by isothermal DSC to obtain the normalized heat flow as a function of time, at the beginning of the reaction. The reaction kinetic was obtained thanks to eq. (2). The autocatalytic model, eq. (3), and the experimental curve $d \alpha / d t=f(\alpha)$ (Figure 5), allow us to determine $k, m$, and $n$ values (Table II).

The kinetic parameter values reported in Table II show complex behaviors with temperature. $k$ increases and follows an Arrhenius law. ${ }^{29,33} m$ and $n$ are not dependent on the temperature. Their evolution describes the physical and chemical behavior of the matrix during the polymerization. $m$ describes the beginning of the autocatalytic reaction. The autocatalytic reaction occurs quickly when $\mathrm{m}$ reach to 0 . Our data do not indicate an evolution of this parameter; that may be attributed to the low temperature of the isothermal experiments and the poor quantity of hydroxyl group catalyzer formed.

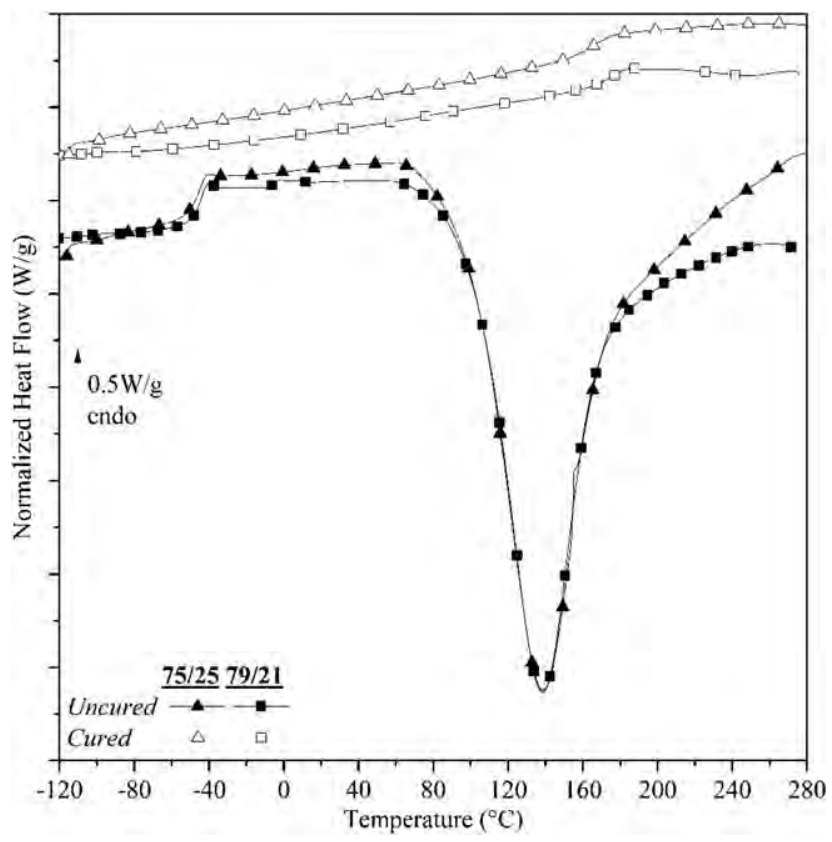

Figure 2. DSC thermograms of uncured and cured poly(epoxy) for two stoichiometric ratios. 
Table I. Thermal Characteristics of the Poly(epoxy) for Two Stoichiometric Ratios (Uncertainties Are Added)

\begin{tabular}{llllll}
\hline $\begin{array}{l}\text { Stoichiometric } \\
\text { ratio }\end{array}$ & Heating & $\begin{array}{l}T_{g 0} \\
\left({ }^{\circ} \mathrm{C}\right)\end{array}$ & $\begin{array}{l}\Delta H_{t=0} \\
\left(\mathrm{~J} \mathrm{~g}^{-1}\right)\end{array}$ & $\begin{array}{l}T_{g} \\
\left({ }^{\circ} \mathrm{C}\right)\end{array}$ & $\begin{array}{l}\Delta \mathrm{Cp} \\
\left(\mathrm{J} \mathrm{g}^{-1} \mathrm{~K}^{-1}\right)\end{array}$ \\
\hline $79 / 21$ & First & -45.2 & 269 & $/$ & 0.69 \\
& & $(0.1)$ & $(17)$ & & $(0.01)$ \\
& Second & $I$ & $I$ & 174 & 0.31 \\
$75 / 25$ & & & $(2)$ & $(0.02)$ \\
& First & -47.8 & 370 & 1 & 0.65 \\
& & $(0.1)$ & $(30)$ & 163 & $(0.01)$ \\
& Second & $I$ & $I$ & $(1)$ & 0.43 \\
& & & & & $(0.01)$ \\
\hline
\end{tabular}

The $n$ parameter is linked to the system gelation. It describes the transition between the autocatalytic phenomenon and the diffusion. ${ }^{32,34}$ When $n$ is above 1 , the kinetic reaction and the sequences mobility decrease quickly, and the amount of crosslink is constant. Our experimental data confirm this behavior: for the highest temperatures, $n$ is above 1 . The $3 \mathrm{D}$ network formation was accelerated by the temperature and the diffusion phenomenon occurs early. It can be observed in Figure 5 that it is consistent with in other study. ${ }^{35}$ Figure 5 shows the influence of the stoichiometric ratio on the reaction kinetics. A hardener excess induces a slight increase of the kinetic reactions for the different temperatures.

\section{Calorimetric Study of Silver Nanocomposites}

A preliminary experiment was carried out to check that solvents used to adjust the viscosity during the spraying process do not modify the polymerization enthalpy. It was carried out with three configurations. The first one is the pristine epoxide resin, the second one is the resin after being put into a furnace at $100{ }^{\circ} \mathrm{C}$ for $20 \mathrm{~min}$, and the last one is the epoxide resin mixed with ethanol

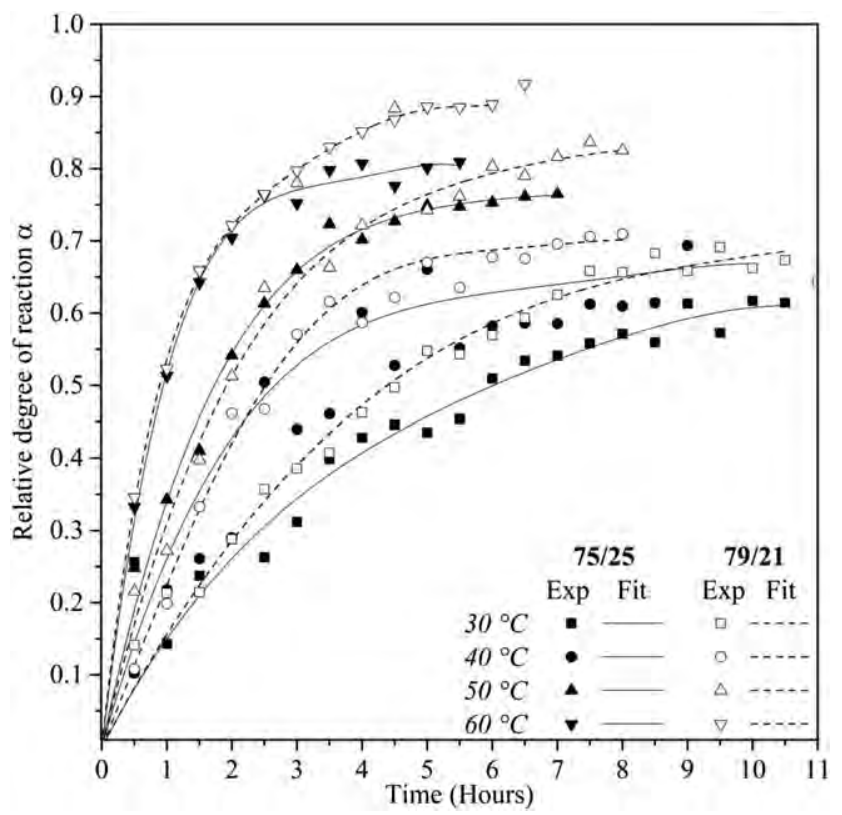

Figure 3. Relative degree of reaction as a function of time for two stoichiometric ratios obtained with the dynamic experiment.
$(0.3 \mathrm{~mL})$ which was then evaporated under the same conditions. The hardener was added after a cooling at room temperature. Thermograms do not show any noteworthy modification after these treatments, the average enthalpy is about $360 \mathrm{~J} \mathrm{~g}^{-1}$ $\left( \pm 20 \mathrm{~J} \mathrm{~g}^{-1}\right)$.

Influence of the AgNWs. The influence of AgNWs was evaluated with $1 \%$ in volume filler ratio ( $8.8 \%$ in weight). Above this value, the mixture becomes too viscous to incorporate properly the hardener, and the enthalpy determination was not repeatable. The stoichiometric ratio is $75 / 25$.

The polymerization enthalpy of the matrix filled with AgNWs is lower than the neat polymer (Table III). This difference may be attributed to a sterical hindrance between the AgNWs and the 2,2-bis(4-hydroxyphenyl) propane of the DGEBA. The chains mobility is reduced and the quantity of crosslinks formed during polymerization is less important. The $T_{g 0}$ and $T_{g}$ values vary in the same way; there is a slight decrease of their value for this filler content. These differences can be explained by a better thermal

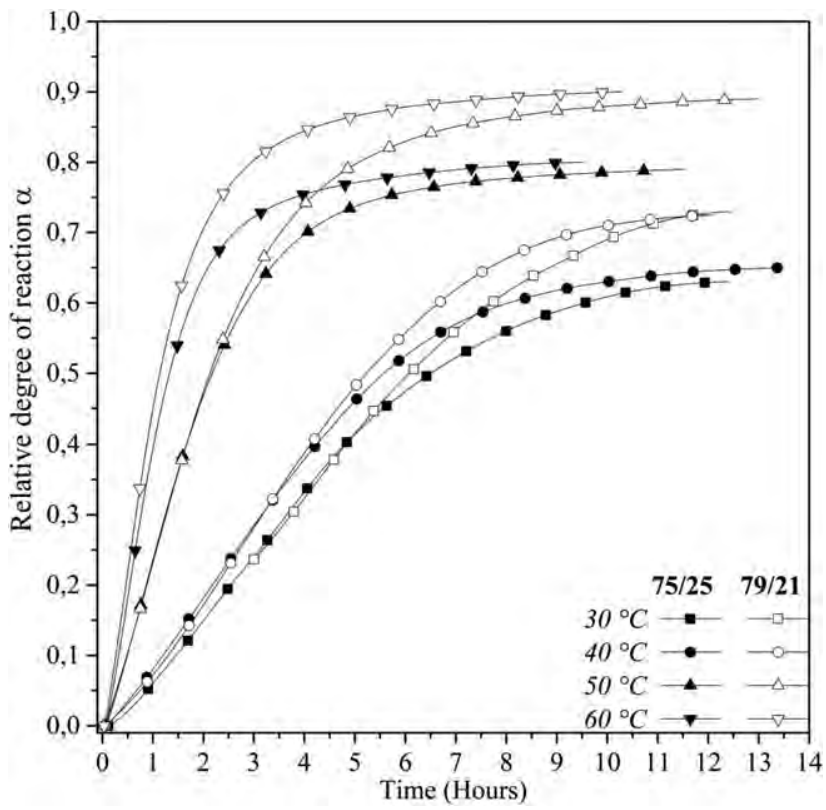

Figure 4. Relative degree of reaction as a function of time for two stoichiometric ratios obtained with the isothermal experiment. 
Table II. Kinetic Parameters at Different Temperatures for Two Stoichiometric Ratios (Uncertainties Are Added)

\begin{tabular}{lllll}
\hline Stoichiometric ratio & $T\left({ }^{\circ} \mathrm{C}\right)$ & $k$ & $m$ & $n$ \\
\hline $75 / 25$ & 30 & 0.0052 & 0.352 & 0.814 \\
& & $(0.0002)$ & $(0.002)$ & $(0.003)$ \\
& 40 & 0.0063 & 0.424 & 0.808 \\
& & $(0.0002)$ & $(0.002)$ & $(0.002)$ \\
& 50 & 0.0123 & 0.291 & 1.010 \\
& & $(0.0002)$ & $(0.003)$ & $(0.005)$ \\
& 60 & 0.0268 & 0.403 & 1.320 \\
$79 / 21$ & & $(0.0002)$ & $(0.005)$ & $(0.004)$ \\
& 30 & 0.0055 & 0.366 & 0.812 \\
& & $(0.0004)$ & $(0.003)$ & $(0.003)$ \\
& 40 & 0.0047 & 0.274 & 0.598 \\
& & $(0.0004)$ & $(0.005)$ & $(0.004)$ \\
& 50 & 0.0109 & 0.291 & 0.975 \\
& & $(0.0002)$ & $(0.002)$ & $(0.004)$ \\
& 60 & 0.0259 & 0.401 & 1.340 \\
& & $(0.0002)$ & $(0.003)$ & $(0.003)$ \\
\hline
\end{tabular}

conductivity. For $T_{g 0}$, that allows lower temperature of chains mobility. For $T_{g}$, the higher thermal conductivity could increase the polymerization kinetic and imply more unreacted products in $3 \mathrm{D}$ network, in addition of steric hindrance which leads to a decrease of the conversion degree (Figure 6). As observed with the variation of the stoichiometric ratio $(3: 2: 1)$, there is a modification of the thermal behavior between dynamic and isothermal studies with matrix filled with the AgNWs at around $40{ }^{\circ} \mathrm{C}$. It is still attributed to the formation of the hydroxyl group during the dynamic analyses.

Kinetic Study of the Composite Poly(epoxy)/AgNWs. The influence of the AgNWs on the kinetic was determined by isothermal DSC, results were reported in Table IV and Figure 7.

Metallic fillers modify $k$ parameter. It increases with temperature, but its values are lower for composite (1\% in volume of AgNWs).

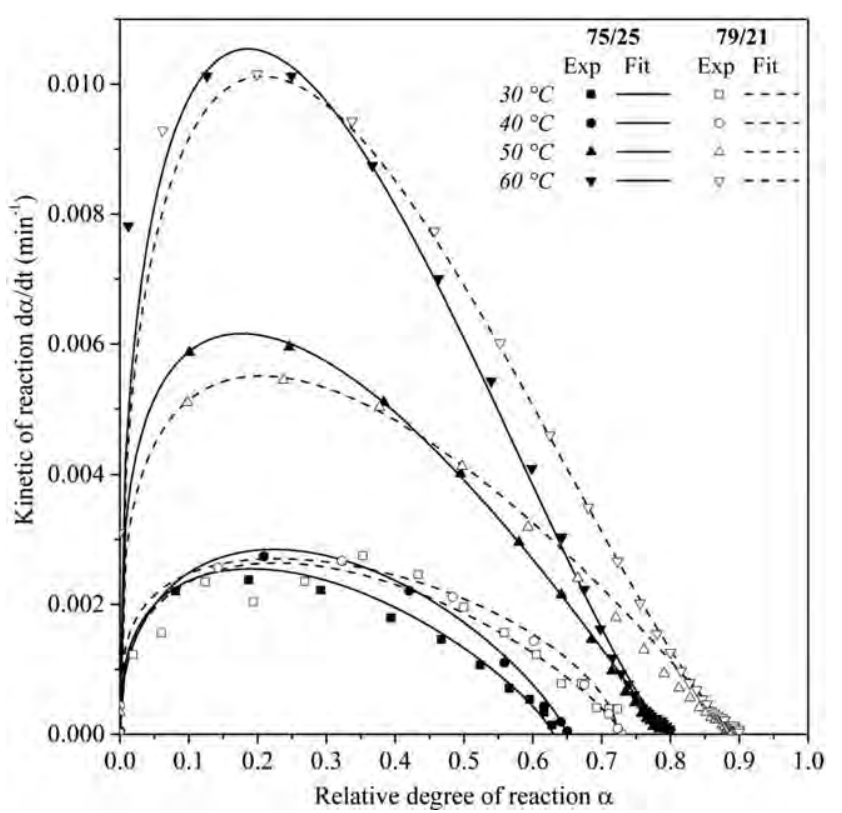

Figure 5. Kinetic of reaction as a function of the relative degree of reaction at different temperatures for two stoichiometric ratios.

It is associated with a modification of the thermal conductivity. Linear regression of the Arrhenius equation has permitted to obtain the activation energy for the polymerization reaction. Values are reported below for the neat epoxy and the composite: $E_{A(0 \% \text { vol })} \approx 63 \mathrm{~kJ} \mathrm{~mol}^{-1}$ versus $E_{A(1 \% \text { vol })} \approx 56 \mathrm{~kJ} \mathrm{~mol}^{-1}$. Such behavior has been observed for an epoxy composite filled with CNTs. $^{36}$

The composite does not need as much energy for the polymerization reaction. The increase of thermal conductivity with AgNWs has been already observed for some matrices. ${ }^{37,38}$

The variation of the $m$ parameter is more pronounced. The thermal conductivity enhancement by the AgNWs could explain the early starting of the autocatalytic reaction. A shift to lower values for the matrix filled with the AgNWs is observed. Unlike the experiments with the stoichiometric ratios, $n$ seems to decrease with the temperature increase. ${ }^{39}$ For the lowest temperatures, the high viscosity of the mixing and the steric hindrance cause a

Table III. Thermal Characteristics of the Matrix for Two Filler Ratios (Uncertainties Are Added). For 1\% Filler Content, Enthalpy Value Was Normalized to the Polymer Content

\begin{tabular}{llllll}
\hline Filler content AgNWs & Heating & $T_{g 0}\left({ }^{\circ} \mathrm{C}\right)$ & $\Delta H_{t=0}\left(\mathrm{~J} \mathrm{~g}^{-1}\right)$ & $T_{g}\left({ }^{\circ} \mathrm{C}\right)$ & $\Delta \mathrm{Cp}\left(\mathrm{J} \mathrm{g}^{-1} \mathrm{~K}^{-1}\right)$ \\
\hline $0 \%$ & First & -47.8 & 370 & 1 & 0.65 \\
& & $(0.1)$ & $(30)$ & & $10.01)$ \\
& Second & $I$ & $I$ & 163 & 0.43 \\
& & & 313 & 1 & $(0.01)$ \\
$1 \%$ & First & -53.6 & $(14)$ & & 0.72 \\
& & $(0.2)$ & & 156 & $(0.04)$ \\
& Second & 1 & & $(1)$ & 0.44 \\
& & & $0.01)$ \\
\hline
\end{tabular}




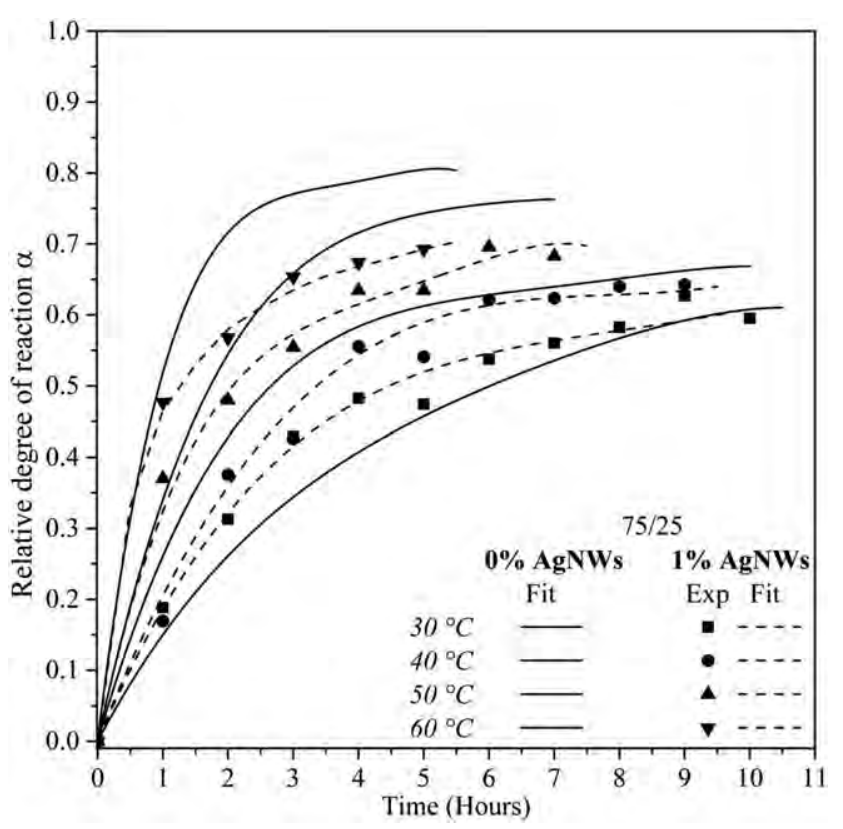

Figure 6. Relative degree of reaction as a function of time for two filler ratios at different temperatures obtained with the dynamic method.

decrease of the sequences mobility. For the highest temperatures, the viscosity decreases but the steric hindrance is the same, the sequences mobility is higher and the diffusion phenomenon occurs later.

Figure 7 shows the influence of AgNWs on the polymerization kinetic. Metallic fillers are responsible for the kinetic increase, and the early starting of the autocatalytic reaction. We also

Table IV. Kinetic Parameters at Different Temperatures for Two Filler Ratios (Uncertainties Are Added)

\begin{tabular}{lllll}
\hline Filler ratio & $T\left({ }^{\circ} \mathrm{C}\right)$ & $k$ & $m$ & $n$ \\
\hline $0 \%$ & 30 & 0.0052 & 0.352 & 0.814 \\
& & $(0.0002)$ & $(0.002)$ & $(0.003)$ \\
& 40 & 0.0063 & 0.424 & 0.808 \\
& & $(0.0002)$ & $(0.002)$ & $(0.002)$ \\
& 50 & 0.0123 & 0.291 & 1.010 \\
& & $(0.0002)$ & $(0.003)$ & $(0.005)$ \\
& 60 & 0.0268 & 0.403 & 1.320 \\
& & $(0.0002)$ & $(0.005)$ & $(0.004)$ \\
& 30 & 0.0081 & 0.500 & 1.20 \\
\hline & & $(0.0004)$ & $(0.003)$ & $(0.01)$ \\
& 40 & 0.0060 & 0.270 & 0.853 \\
& & $(0.0002)$ & $(0.004)$ & $(0.002)$ \\
& 50 & 0.0103 & 0.062 & 0.817 \\
& & $(0.0002)$ & $(0.003)$ & $(0.003)$ \\
& 60 & 0.0199 & 0.131 & 1.050 \\
& & $(0.0003)$ & $(0.003)$ & $(0.002)$ \\
\hline & & & & \\
\hline & & & & \\
& & &
\end{tabular}

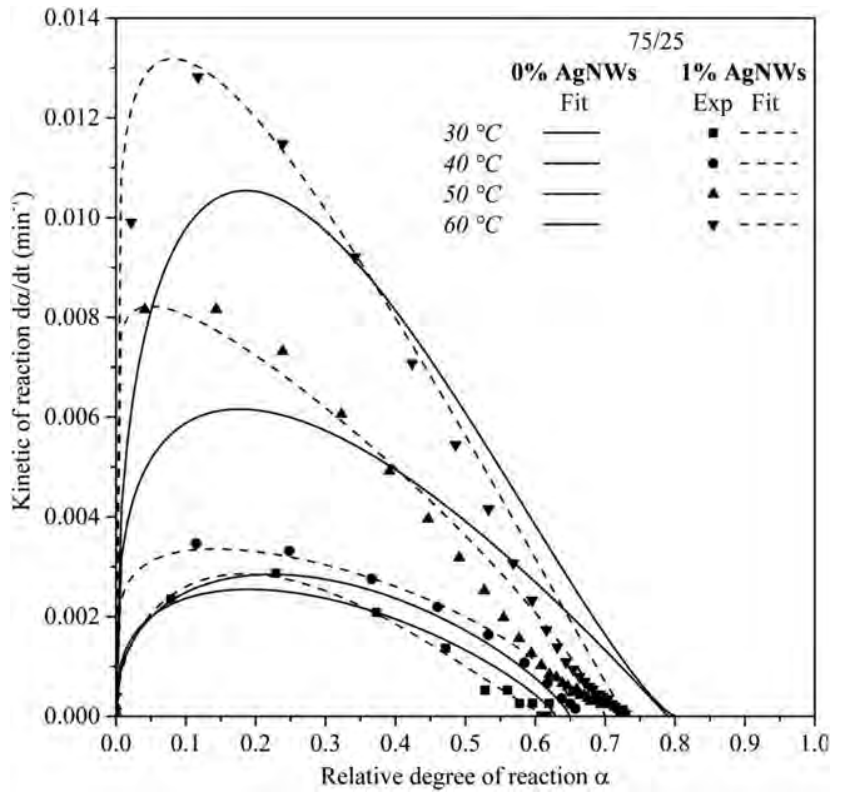

Figure 7. Kinetic of reaction as a function of the relative degree of reaction at different temperatures for two filler ratios.

observe a modification of the thermal transition between autocatalytic and diffusion phenomena.

\section{Electrical Measurements}

Bulk Conductivity. Bulk conductivity measurements are illustrated in Figure 8. The neat poly(epoxy) conductivity is around $10^{-12} \mathrm{~S} \mathrm{~m}^{-1}$. With AgNWs dispersion, the value above the percolation threshold is close to $4.10^{2} \mathrm{~S} \mathrm{~m}^{-1}$ for $8 \%$ in volume. It is in agreement with the literature for a random dispersion of silver fillers. ${ }^{17,24,25,37,38}$ The percolation threshold obtained is around $0.7 \%$ in volume. The threshold value is higher than the theoretical value ${ }^{40}(0.3 \%$ in volume). The formation of bundles might explain the gap. Thanks to experimental value, the apparent aspect ratio is calculated near $\xi=100$ which is not close to the mean value ${ }^{25}$ obtained by electronic microscopic observations (experimental value $\xi_{\exp }=220$ ).

Kamal and Sourour ${ }^{29}$ have modified Balberg et al.'s formalism $^{41,42}$ (eq. (7)) to include the formation of aggregates into the percolating cluster (eq. (8)).

$$
V_{\mathrm{ex}}=\frac{32}{3} \pi r^{3}+8 \pi L r^{2}+4 L^{2} r\langle\sin \theta\rangle
$$

With total excluded volume $V_{\mathrm{ex}}, L$ is the stick length, $r$ is the stick radius, $\theta$ is the angle between two sticks, and $\langle\sin \theta\rangle$ is the sine mean value of each angle $\theta$ between charges network introduced in the matrix.

$$
V_{\mathrm{ex}}=\pi L^{2} r=\frac{L}{r} V_{\text {stick }}
$$

$V_{\text {stick }}$ is the volume of one stick.

$$
\xi=\frac{L}{D} \Rightarrow V_{e x}=\frac{L}{r} V_{\text {stick }} N_{c}=\frac{L}{r} p_{c}=2 \cdot \frac{L}{D} p_{c}=2 \xi p_{c}=1.41
$$

With $\xi$ is the aspect ratio of the stick, $N_{c}$ is the critical concentration, the site percolation critical occupation probability $p_{c}$, and $D$ is the diameter of the stick. 


$$
\begin{gathered}
\xi p_{c} \approx 0.7 \\
\xi p_{c} \approx 0.7 \sqrt{n}
\end{gathered}
$$

With $n$ the number of sticks that are included into the aggregate.

Finally, $n=5$ is found. The aggregates are formed by five sticks. The apparent aspect ratio is lower than the model prediction due to the process which implies the formation of some aggregates during the stirring or the spraying of the mixing.

Above the percolation threshold, the electrical behavior is described by the following power law model proposed by Stauffer and Aharony [eq. (9)]. ${ }^{43}$

$$
\sigma=\sigma_{0}\left(p-p_{c}\right)^{t}
$$

With $\sigma_{0}$ conductivity of a sample filled with $100 \%$ of AgNWs (we can assume this value to the electrical conductivity of a bundle of AgNWs pressed), $p$ is the filler volume ratio, $p_{c}$ is the filler ratio at percolation threshold, and $t$ is the critical exponent related to the dimensionality $d$ of the system. $t$ varies from 1.1 to 1.3 for $d=2$, and between 1.6 and 2 for $d=3 .{ }^{43}$ Critical exponent $t$ has been determined (inset Figure 8) and is equal to $2.2 \pm 0.1$. This value is slightly higher than predicted by Stauffer's model for a 3D dispersion. It has been associated with the presence of aggregates. Cortes et al. ${ }^{25}$ have found a close value for composites PEKK/AgNWs.

Surface Resistivity. The surface resistivity was measured for coatings filled with $0-8 \%$ in volume of AgNWs. The lowest value of resistivity is about $13 \mathrm{~m} \Omega \mathrm{sq}^{-1}$ for $8 \%$ in volume (Figure 9). The percolation threshold is about $1 \%$.

This percolation threshold value is lower than the one obtained by Balberg's model for 2D percolation threshold ${ }^{40,41}$ [eq. (16)].

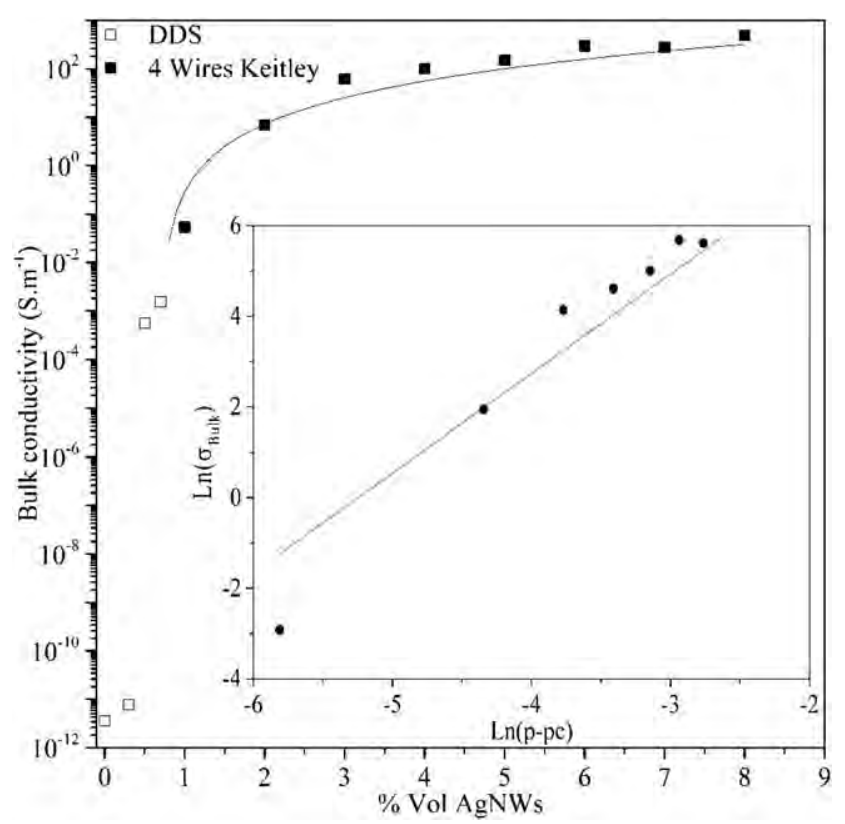

Figure 8. Bulk conductivity as a function of AgNWs \% in vol. and bulk conductivity fit. Inset: $\operatorname{Ln}(\sigma \mathrm{bulk})$ as a function of $\operatorname{Ln}(\mathrm{p}-\mathrm{pc})$. Solid line is the linear fit for bulk conductivity.

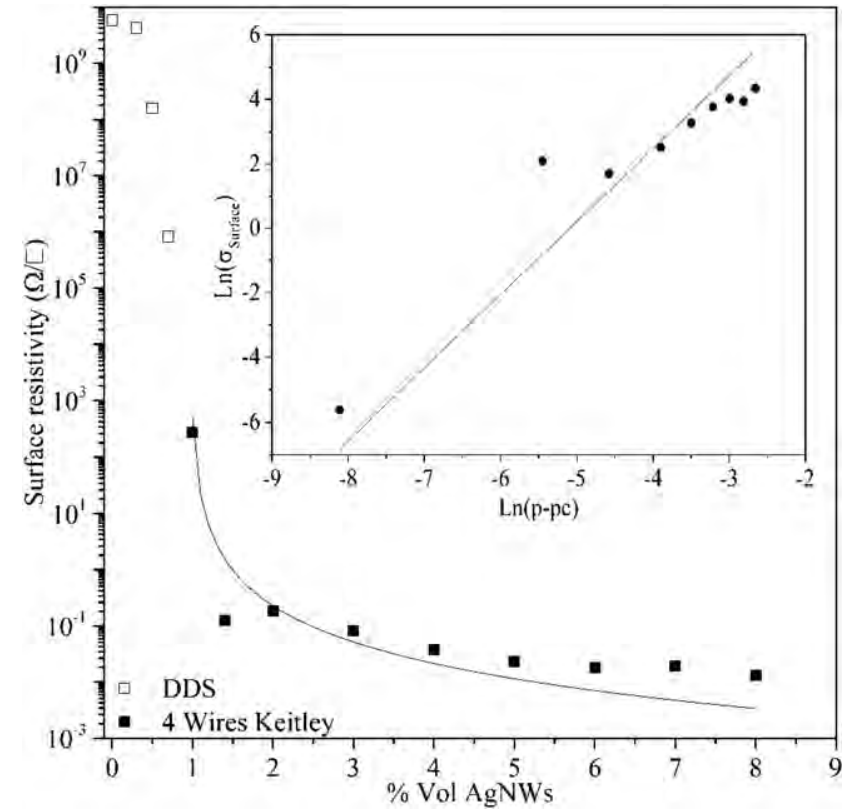

Figure 9. Surface resistivity as a function of AgNWs \% in vol. and surface resistivity fit. Inset: $\operatorname{Ln}(\sigma$ surface $)$ as a function of $\operatorname{Ln}(\mathrm{p}-\mathrm{pc})$. Solid line is the linear fit for surface conductivity.

$$
A_{\text {stick }}=\pi \cdot D^{2}+D L
$$

$A_{\text {stick }}$ is the stick area, $D$ is the stick diameter, and $L$ is the stick length.

$$
A_{\mathrm{ex}}=4 D L+\pi D^{2}+\left(\frac{L}{2 \theta}\right)^{2} \cdot(4 \theta-2 \sin (2 \theta))
$$

$A_{\text {ex }}$ is the total excluded area and $\theta$ is the angle between two sticks.

$$
\begin{gathered}
\text { Isotropic orientation } \theta=\frac{\pi}{2} \Rightarrow A_{\mathrm{ex}}\left(\theta=\frac{\pi}{2}\right)=4 D L+\pi D^{2}+\frac{2 L^{2}}{\pi} \\
\xi=\frac{L}{D} \Rightarrow A_{\mathrm{ex}}\left(\theta=\frac{\pi}{2}\right)=4 D^{2} \xi+\pi D^{2}+\left(\frac{2 D^{2} \xi^{2}}{\pi}\right)
\end{gathered}
$$

$\xi$ is the aspect ratio of the stick.

$$
\begin{gathered}
\frac{A_{\mathrm{ex}}}{A_{\text {stick }}}=\frac{4 D^{2} \xi+\pi D^{2}+\left(\frac{2 D^{2} \xi^{2}}{\pi}\right)}{\pi \cdot D^{2}+D L}=\frac{4 \xi+\pi+\frac{2 \xi 2}{\pi}}{\xi+\pi} \\
\text { When } \mathrm{L} \gg \mathrm{D} \Rightarrow \xi \gg 1 \frac{A_{\mathrm{ex}}}{A_{\text {stick }}}=\frac{2 \xi}{\pi} \\
A_{\text {ex }} \cdot N_{c}=A_{\mathrm{ex}_{c}}, A_{\text {stick }} \cdot N_{c}=A_{\text {stick }_{c}} \text { et } p_{c}=1-e^{-A_{\text {stick }}} \approx A_{\text {stick }_{c}} \\
A_{\mathrm{ex}_{\mathrm{c}}}=3.57 \Rightarrow 3.57=\frac{2 \xi}{\pi} p_{c} \Rightarrow p_{c} \approx \frac{5.61}{\xi}
\end{gathered}
$$

$A_{\mathrm{ex}_{c}}$ is the critical total excluded area, $A_{\text {stick }_{c}}$ is the critical area of a stick, $N_{c}$ is the critical concentration and the site percolation critical occupation probability $p_{c}$.

With experimental value of the percolation threshold and eq. (16), the apparent aspect ratio is equal to $\xi=600$, which is not close to our experimental value of AgNWs $\left(\xi_{\exp }=220\right) .{ }^{25}$ 
The discrepancy between these two values could be explained by the orientation of some fillers [Figure 1(b)]. This hypothesis is confirmed by the Stauffer coefficient around $2.3 \pm 0.1$, classically close to 1.2 for a two-dimensional system.

Introduction of AgNWs in poly(epoxy) matrix permits to obtain a large decrease of surface resistivity, about 12 decades for $5 \%$ in volume of AgNWs. Current coatings based on silver flakes fillers obtain an equivalent electrical resistivity value. ${ }^{44}$ However, their low aspect ratio, around $15,{ }^{45}$ induces a higher percolation threshold, about $20 \%$ in volume. This very important fillers content implies lower mechanical properties.

\section{CONCLUSIONS}

The influence of AgNWs on thermal and electrical behaviors of a poly(epoxy) coating system was studied. The SEM observations have permitted to show a homogenous dispersion, with a slight orientation due to the spray processing. The AgNWs' aspect ratio is maintained. The influence of the stoichiometric ratio (i.e., 79/21 or 75/25) was studied by dynamic and isothermal calorimetric techniques. A hardener excess causes a decrease about $9 \%$ of the maximum relative degree of reaction. It can be explained by a fast increase of the matrix viscosity and a sequences mobility decrease. For low temperatures isotherms $\left(\leq 40{ }^{\circ} \mathrm{C}\right)$, the reaction kinetic is slower than in dynamic mode due to the reaction type, that is, autocatalytic. There is not enough energy to create a large quantity of catalyzer, that is, hydroxyl group.

The AgNWs introduction causes a decrease of the relative degree of reaction due to the steric hindrance. AgNWs increase the thermal conductivity and the reaction kinetic. The activation energy of the crosslinking reaction decreases.

Electrical experiments highlight the interest of AgNWs introduction in polymer coating. AgNWs decrease the surface resistivity by 12 decades, up to $13 \mathrm{~m} \Omega \mathrm{sq}^{-1}$. As far as we know, it is the lowest value for coating with very low filler content, more than twice lighter than classical commercial coatings for lightning strike protection. AgNWs increase the bulk conductivity by 14 decades, up to $4 \times 10^{2} \mathrm{~S} \mathrm{~m}^{-1}$. The AgNWs aspect ratio permits to obtain a percolation threshold with a very low quantity of fillers, $1 \%$ in surface and $0.7 \%$ in volume. This coating has a great interest for a lightning strike protection of aircrafts thanks to its high electrical conductivity for low filler ratio.

\section{ACKNOWLEDGMENTS}

These results were obtained under the research project "COMPINNOVTD" at the IRT Saint Exupéry. The author would like to thank the industrial and academic members of the IRT who supported this project through their contributions, both financial and in terms of specific knowledge: Industrial members: Airbus Operations, ArianeGroup, Airbus Helicopters, Airbus Group Innovations, STELIA Aerospace, and Thales Alenia Space. Academic members: CIRIMAT, UPS, and CNRS. The authors would also like thank the Commissariat Général aux Investissements and the Agence Nationale de la Recherche for their financial support in the Programme d'Investissement d'Avenir (PIA).

\section{REFERENCES}

1. Bathias, C.; Bouteveille, A.; Wolff, C.; Bouteveille, U. Matériaux Composites. Technique et ingénierie; Dunod, Paris, 2005.

2. Pierre, C. Process for the Manufacture of Thermosetting Synthetic Resins by the Polymerization of Alkylene Oxide Derivatives, 1948. Patent number US2444333A.

3. Lonjon, A.; Demont, P.; Dantras, E.; Lacabanne, C. J. Non Cryst. Solids. 2012, 358, 1859.

4. Hochberg, F. Method of Making Electrically Conductive Polystyrene Articles 1955. Patent number US2721357A.

5. Sandler, J.; Shaffer, M. S.; Prasse, T.; Bauhofer, W.; Schulte, K.; Windle, A. Polymer (Guildf). 1999, 40, 5967.

6. Barrau, S.; Demont, P.; Peigney, A.; Laurent, C.; Lacabanne, C. Macromolecules. 2003, 36, 5187.

7. Causse, N.; Benchimol, S.; Martineau, L.; Carponcin, D.; Lonjon, A.; Fogel, M.; Dandurand, J.; Dantras, E.; Lacabanne, C. J. Therm. Anal. Calorim. 2015, 119, 329.

8. Liao, K.-H.; Qian, Y.; Macosko, C. W. Polymer (Guildf). 2012, 53, 3756.

9. Shevchenko, V. G.; Polschikov, S. V.; Nedorezova, P. M.; Klyamkina, A. N.; Shchegolikhin, A. N.; Aladyshev, A. M.; Muradyan, V. E. Polymer (Guildf). 2012, 53, 5330.

10. Ali Raza, M.; Westwood, A.; Stirling, C.; Brydson, R.; Hondow, N. J. Appl. Polym. Sci. 2012, 126, 641.

11. Plumer, J.; Robb, J. IEEE Trans. Electromagn. Compat. 1982, EMC-24, 158.

12. Gagné, M.; Therriault, D. Prog. Aerosp. Sci. 2014, 64, 1.

13. Fisher, F. A.; Plurner, J. A. Lightning Protection of Aircraft; Volume 1008 de NASA reference publication; National Aeronautics and Space Administration, Scientific and Technical Information Office; for sale by the Supt. of Docs., U.S. Govt.Print.Off., 1977.

14. Gurland, J. Trans. Metall. Soc. AIME. 1966, 236, 642.

15. Untereker, D.; Lyu, S.; Schley, J.; Martinez, G.; Lohstreter, L. ACS Appl. Mater. Interfaces. 2009, 1, 97.

16. Lonjon, A.; Laffont, L.; Demont, P.; Dantras, E.; Lacabanne, C. J. Phys. Chem. C. 2009, 113, 12002.

17. Audoit, J.; Laffont, L.; Lonjon, A.; Dantras, E.; Lacabanne, C. Polymer (Guildf). 2015, 78, 104.

18. Nguyen, T. H. L.; Quiroga Cortes, L.; Lonjon, A.; Dantras, E.; Lacabanne, C. J. Non Cryst. Solids. 2014, $385,34$.

19. Wang, S.; Cheng, Y.; Wang, R.; Sun, J.; Gao, L. ACS Appl. Mater. Interfaces. 2014, 6, 6481.

20. Ramachandran, L.; Lonjon, A.; Demont, P.; Dantras, E.; Lacabanne, C. Mater. Res. Express. 2016, 3, 85027.

21. Stejskal, J. Chem. Pap. 2013, 67, 814.

22. Lonjon, A.; Demont, P.; Dantras, E.; Lacabanne, C. J. Non Cryst. Solids. 2012, 358, 236.

23. Moreno, I.; Navascues, N.; Irusta, S.; Santamaría, J. IOP Conf. Ser. Mater. Sci. Eng. 2012, 40, 12001. 
24. Lonjon, A.; Caffrey, I.; Carponcin, D.; Dantras, E.; Lacabanne, C. J. Non Cryst. Solids. 2013, 376, 199.

25. Cortes, L. Q.; Lonjon, A.; Dantras, E.; Lacabanne, C. J. Non Cryst. Solids. 2014, 391, 106.

26. Sun, Y.; Yin, Y.; Mayers, B. T.; Herricks, T.; Xia, Y. Chem. Mater. 2002, 14, 4736.

27. Sun, Y.; Xia, Y. Adv. Mater. 2002, 14, 833.

28. Wiley, B.; Sun, Y.; Xia, Y. Acc. Chem. Res. 2007, 40, 1067.

29. Kamal, M. R.; Sourour, S. Polym. Eng. Sci. 1973, 13, 59.

30. Piloyan, G. O.; Ryabchikov, I. D.; Novikova, O. S. Nature. 1966, 212, 1229.

31. Riccardi, C. C.; Adabbo, H. E.; Williams, R. J. J. J. Appl. Polym. Sci. 1984, 29, 2481.

32. Horie, K.; Hiura, H.; Sawada, M.; Mita, I.; Kambe, H. J. Polym. Sci. Part A: Polym. Chem. 1970, 8, 1357.

33. El Sawi, I.; Olivier, P. A.; Demont, P.; Bougherara, H. J. Appl. Polym. Sci. 2012, 126, 358.

34. Mita, I.; Okuyama, H. J. Polym. Sci. Part A: Polym. Chem. 1971, 9, 3437.

35. Villanueva, M.; Núñez, L.; Núñez, M. R.; Rial, B.; Fraga, L.; Montserrat, S. J. Therm. Anal. Calorim. 2002, 70, 45.
36. Vijayan, P. P.; Puglia, D.; Rastin, H.; Saeb, M. R.; Shojaei, B.; Formela, K. Prog. Org. Coat. 2017, 108, 75.

37. Chen, C.; Wang, H.; Xue, Y.; Xue, Z.; Liu, H.; Xie, X.; Mai, Y.-W. Compos. Sci. Technol. 2016, 128, 207.

38. Rivière, L.; Lonjon, A.; Dantras, E.; Lacabanne, C.; Olivier, P.; Gleizes, N. R. Eur. Polym. J. 2016, 85, 115.

39. Esmizadeh, E.; Yousefi, A. A.; Naderi, G. Iran. Polym. J. 2015, 24, 1.

40. Balberg, I.; Anderson, C. H.; Alexander, S.; Wagner, N. Phys. Rev. B. 1984, 30, 3933.

41. Balberg, I.; Binenbaum, N. Phys. Rev. B. 1983, 28, 3799.

42. Balberg, I.; Binenbaum, N.; Wagner, N. Phys. Rev. Lett. 1984, 52, 1465.

43. Stauffer, D.; Aharony, A. Introduction To Percolation Theory. Vol. 6, Taylor et Francis, London, 1994.

44. Merilampi, S.; Laine-Ma, T.; Ruuskanen, P. Microelectron. Reliab. 2009, 49, 782.

45. Marcq, F.; Demont, P.; Monfraix, P.; Peigney, A.; Laurent, C.; Falat, T.; Courtade, F.; Jamin, T. 2011. 